ÁREA TEMÁTICA: EDUCAÇÃO AMBIENTAL

\title{
SALA VERDE PARAÍBA DO SUL
}

Tulio Cezar de Aguiar Oliveira - tuliodeaguiar@gmail.com UniFOA

Anna Paula de Oliveira Santos - paulaannaoliveira@ hotmail.com UniFOA

Shane Aparecida Soares Goulart - shane.goulart@foa.org.br UniFOA

Ana Carolina Callegario Pereira - ana.callegario@foa.org.br UniFOA 


\section{RESUMO}

O Projeto Sala Verde, coordenado pelo Ministério do Meio Ambiente (DEA/MMA) incentiva a implantação de espaços socioambientais para atuarem como potenciais focos de informação e formação ambiental. $\mathrm{O}$ objetivo básico de uma Sala Verde é a democratização e disponibilização da informação ambiental e a facilitação da chegada dos materiais didáticos de cunho ambiental distribuídos pelo MMA, à comunidade. Trata-se de um espaço, que além de disponibilizar o acesso à informação, ofereça também a possível reflexão e construção do pensamento ou da ação ambiental. "Sala Verde é um espaço definido, vinculado a uma instituição pública ou privada, que poderá se dedicar a projetos, ações e programas educacionais voltados à questão ambiental. Deve cumprir um papel dinamizador, numa perspectiva articuladora e integradora, viabilizando iniciativas que propiciem uma efetiva participação dos diversos segmentos da sociedade na gestão ambiental, seguindo uma pauta de atuação permeada por ações educacionais, que caminhem em direção à sustentabilidade" (Ministério do Meio Ambiente, 2015). Atualmente o projeto Salas Verdes conta com 359 salas em todo o território brasileiro, distribuídas em quase todos os estados. As salas são em maioria localizadas em prefeituras municipais, secretarias de educação, secretarias de meio ambiente, institutos federais e universidades, porém elas também estão presentes em alguns conselhos gestores de Unidades de Conservação e ONG's.

Palavras Chave: Educação ambiental, comunidade, meio ambiente. 


\section{INTRODUÇÃO/OBJETIVO}

Os problemas ambientais tem sido uma preocupação nos últimos anos principalmente devido ao esgotamento de muitos recursos naturais que antigamente acreditavam-se ser infinitos. Segundo D’isep (2009), a raridade desses recursos é evidenciada na constatação de suas limitações, escassez e caráter finito, somado ao aumento de sua demanda em razão dos processos de produção e consumo.

Dependendo do tipo de resíduo lançado inadequadamente no ambiente, o mesmo pode contaminar o solo, águas superficiais e subterrâneas, responsáveis pelo abastecimento da população. Esse é o caso, por exemplo, do óleo de cozinha, que conforme Reis e Fleck (2008) podem trazer riscos para população e para o ambiente, havendo a necessidade de se estabelecer regulamentação técnica especifica para seu descarte.

Sendo assim, entende-se ser a educação ambiental uma estratégia para que haja uma mudança de pensamento e atitude, e também para expor as relações existentes entre os seres vivos e os ciclos da natureza contribuindo, portanto, para o desenvolvimento de um espírito de responsabilidade e solidariedade entre os indivíduos e as sociedades (AMÂNCIO, 2005).

\section{METODOLOGIA}

A Sala Verde Paraíba do Sul localiza-se no Centro Universitário de Volta Redonda, Campus Olézio Galotti - UniFOA/RJ. Com o objetivo de integrar a Sala Verde ao cotidiano do Centro Universitário, foi realizado um convite aos gestores institucionais e coordenadores de curso para que os mesmos formalizassem em seus setores de atuação a divulgação do espaço aos docentes e discentes, incentivando sua participação nas ações. Atualmente a Sala Verde conta com a participação de 26 discentes dos cursos de Engenharia Ambiental, Design, Engenharia Civil, Ciências Biológicas, Publicidade e Propaganda, Engenharia de Produção e Medicina. 

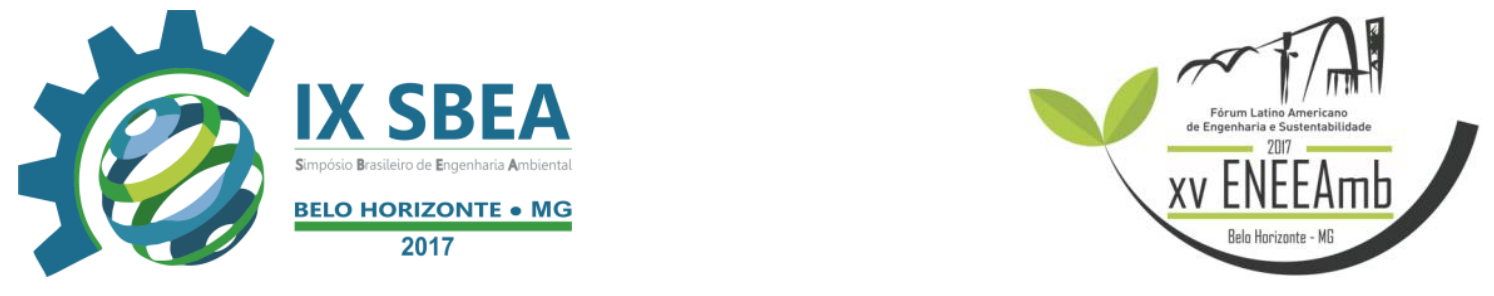

Para a realização e consolidação das propostas são realizadas reuniões ordinárias, que ocorrem às quartas feiras, às 16h, na própria sala. Nessas reuniões são abordados temas referentes à educação ambiental e sustentabilidade, planejamento para a execução de atividades realizadas interna e externamente, recepção de entidades que solicitam ações da Sala Verde, avaliação dos resultados das ações e formalização dos resultados em forma de relatório, que deve ser enviado anualmente ao MMA.

Busca-se também propor eventos em datas comemorativas, como dia da água, dia da árvore, e outros, para massificar a consciência ambiental na comunidade e difundir cada vez mais a educação ambiental em todas as esferas sociais.

\section{RESULTADOS E DISCUSSÃO}

O Ministério do Meio Ambiente encaminha para as Salas Verdes vídeos com a temática ambiental. A Sala Verde apresenta esses vídeos para a comunidade em eventos internos e externos. A (Fig.1) é referente à exibição do Cine Verde às crianças do Quilombo de Santana, localizado em QuatisRJ.

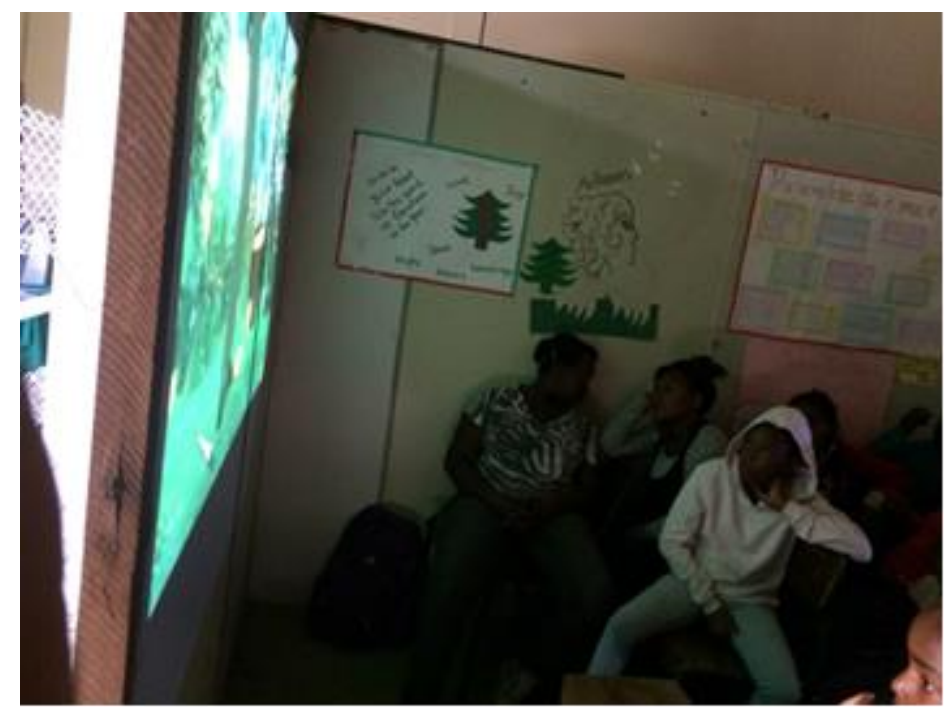

Figura 1: Cine Verde 
Em 2016 os projetos e ações foram iniciados pela capacitação dos monitores da Sala Verde para ministrarem a "Oficina de Brinquedos - parte I" (Fig. 2), onde os alunos monitores da Sala Verde aprenderam técnicas de montagem de brinquedos a partir de material reciclado e determinaram quais brinquedos seriam propostos nas oficinas propriamente ditas.

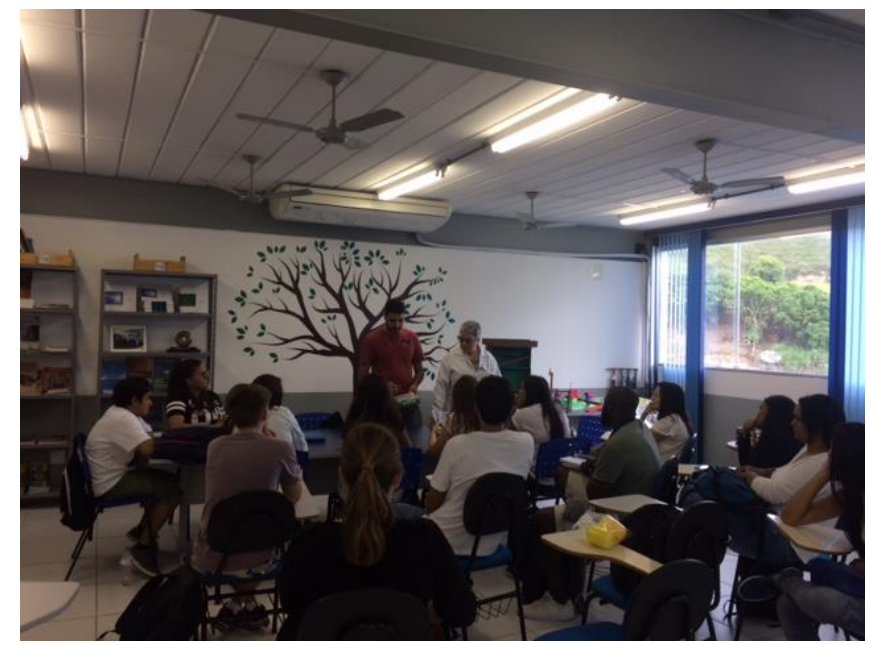

Figura 2: Oficina de brinquedos - parte I

Em seguida foi realizada a segunda capacitação dos monitores da Sala Verde para a "Oficina de Brinquedos - parte II" (Fig. 3). Nessa etapa os monitores se especializaram na confecção dos brinquedos determinados para serem propostos nas oficinas oficiais. 

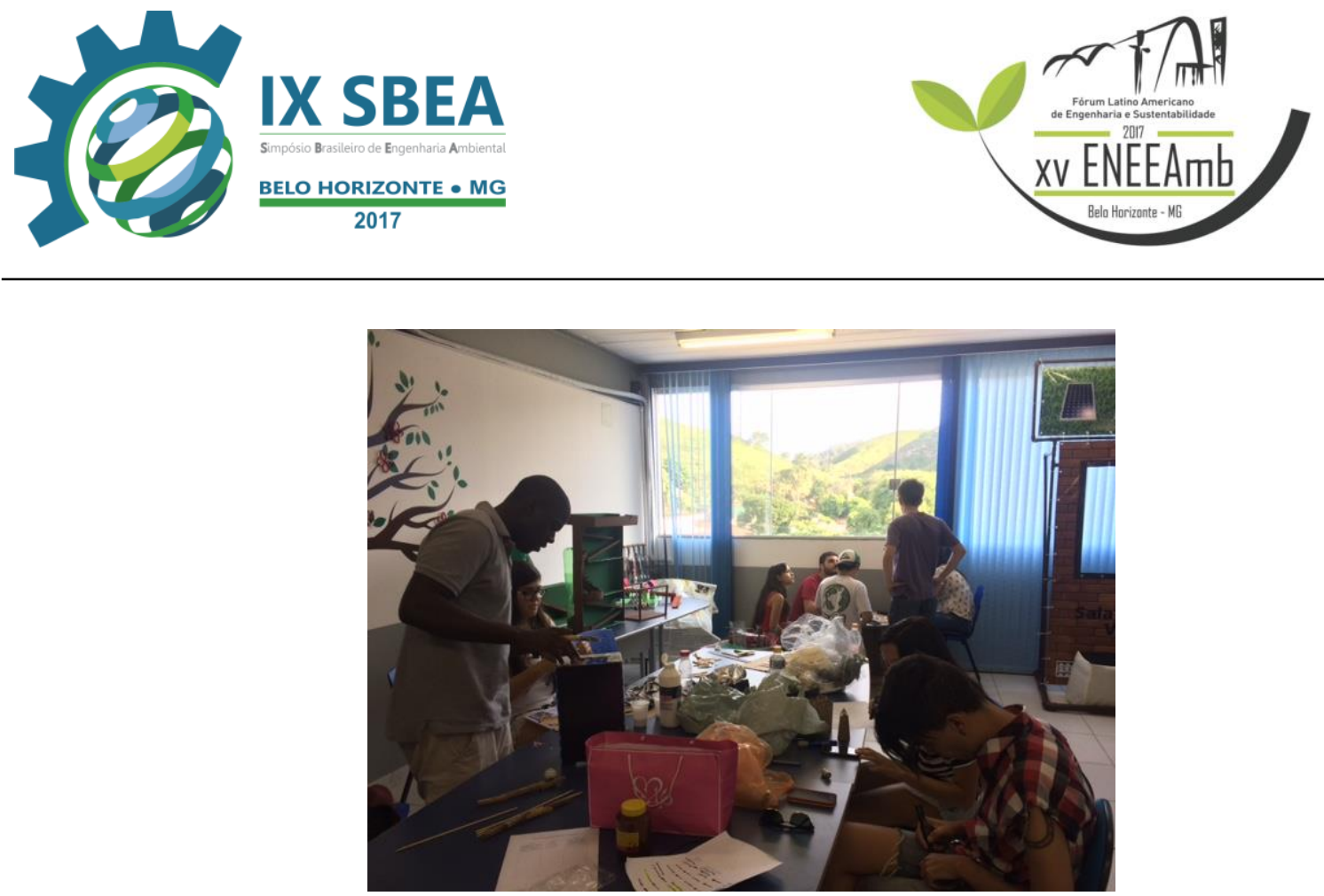

Figura 3: Oficina de brinquedos parte II

Um dos projetos realizado no ano de 2015, o Aquecipet (Fig. 4), foi apresentado em 2016 para uma emissora de televisão em um programa cujo tema era sustentabilidade.

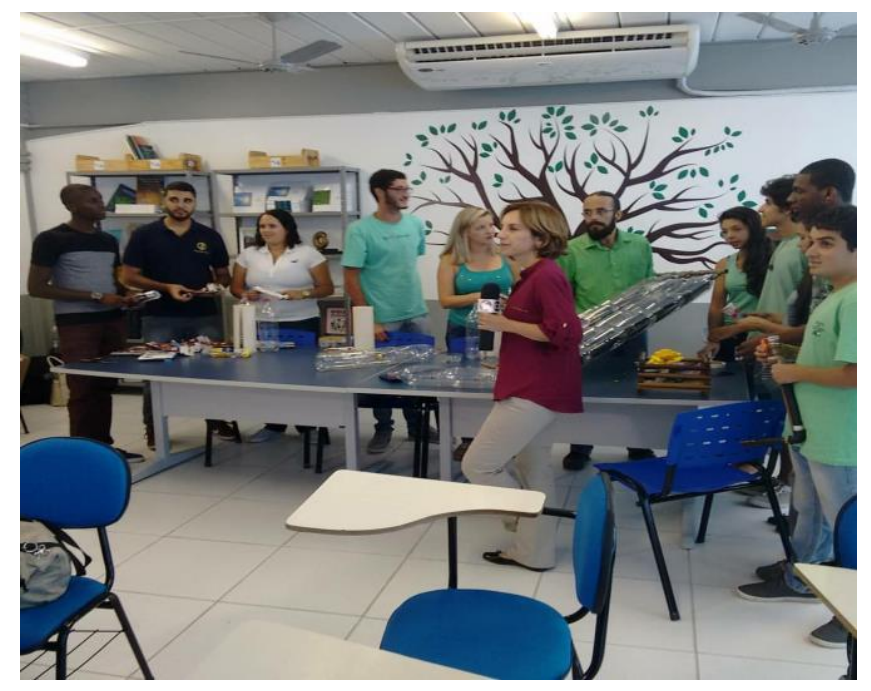

Figura 4: Participação no Rio Sul Revista

Em uma das visitas da Sala Verde ao Quilombo de Santana, no município de Quatis, foi observado pelos monitores que as crianças não tinham material escolar para conseguirem desenvolver um estudo satisfatório. Assim, foi 
realizada uma campanha de arrecadação de material escolar, que foi entregue em uma feira de ciências proposta pela Sala Verde às crianças e adolescentes quilombolas (fabricação de tinta de terra, lousa negra e a água que pega fogo) (Fig. 5).

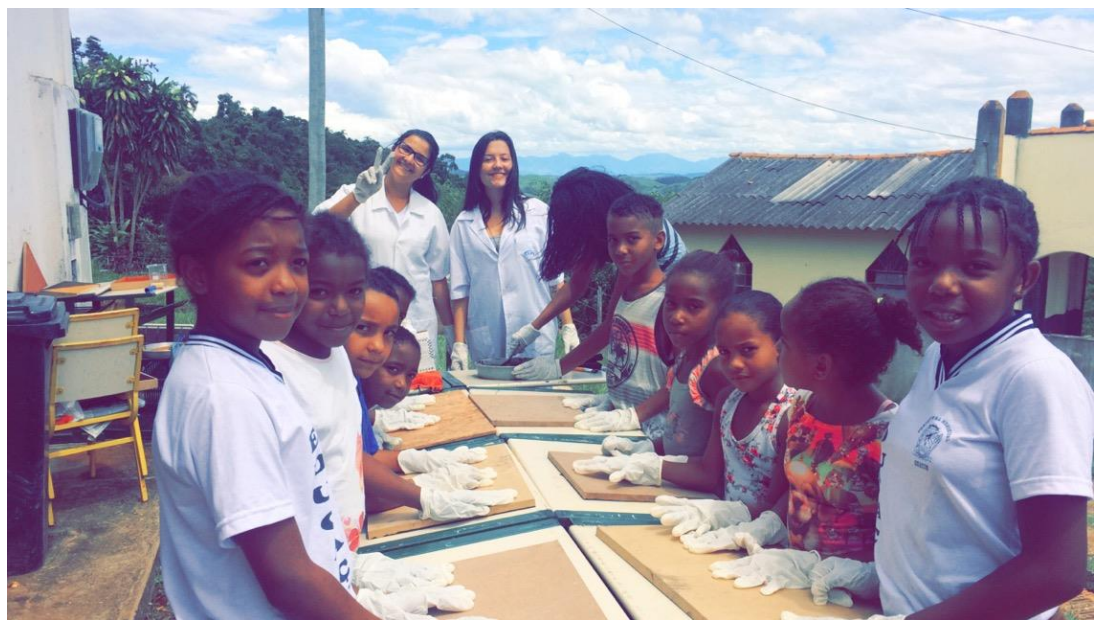

Figura 5: Visita ao Quilombo de Santana em Quatis-RJ

Oficina de brinquedos oferecida para a Escola Municipal Paulo Freire (Fig. 6), localizada no município de Pinheiral-RJ.

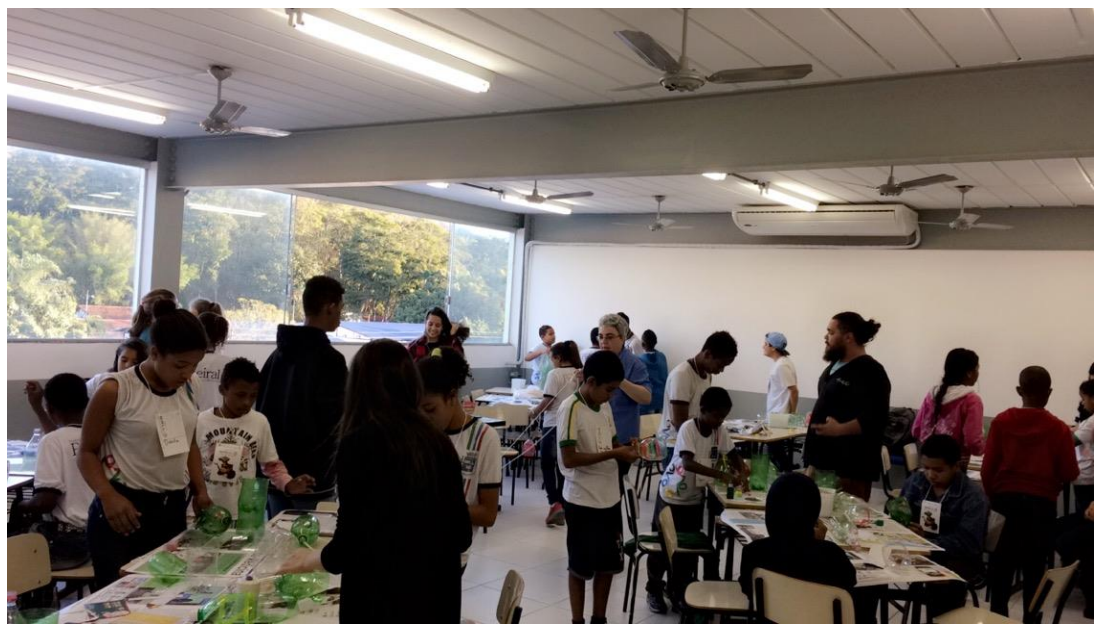

Figura 6: Oficina de brinquedos 
Foi oferecida uma "Oficina de reciclagem" (Fig. 7) para o Colégio Estadual Célio Barbosa Anchite - Pinheiral, onde os alunos aprenderam na pratica, que realmente é possível reciclar materiais inimagináveis.

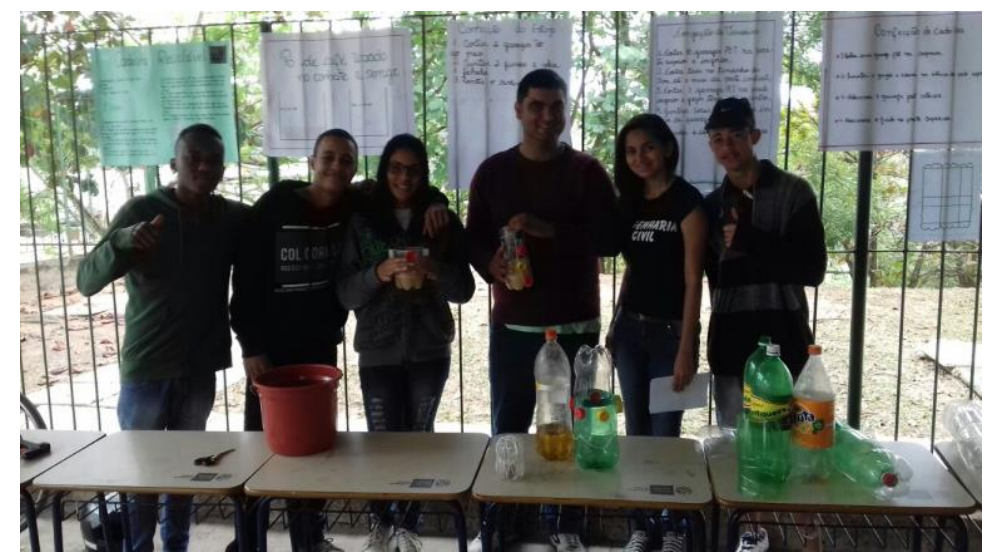

Figura 7: Oficina de reciclagem

Pensando em construir um espaço de convivência para a Sala Verde foi proposto montar um espaço feito de bambu, na forma de um domo geodésico (Fig.8). Uma equipe de alunos das Engenharias Civil e Ambiental começaram a montar em escala menor como seria o espaço.

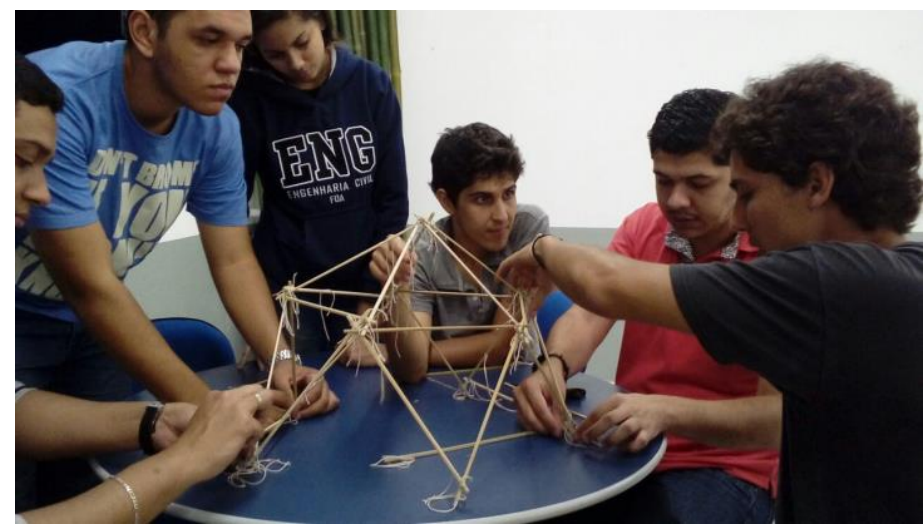

Figura 8: Projeto Domo Geodésico Parte I 
Para divulgar os conteúdos que a Sala Verde propõe e assim conseguir atingir mais discentes na Instituição, a equipe se propôs a construir um totem (Fig.9), e nele demostrar as atividades que estão sendo realizadas, havendo assim motivação para novos discentes participarem da equipe Sala Verde.

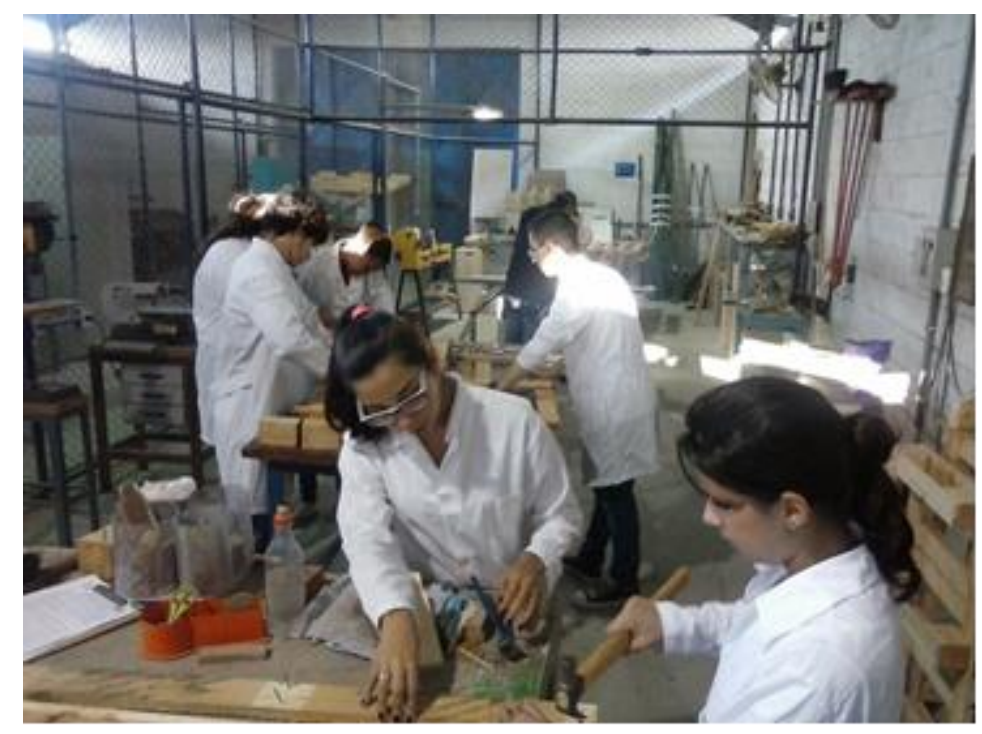

Figura 9: Totem Sala Verde

Outro evento proposto no ano de 2016 foi uma palestra sobre as “Energias Renováveis" (Fig. 10). Nessa palestra os alunos do UniFOA aprenderam um pouco mais sobre a importância das energias renováveis para o planeta. 


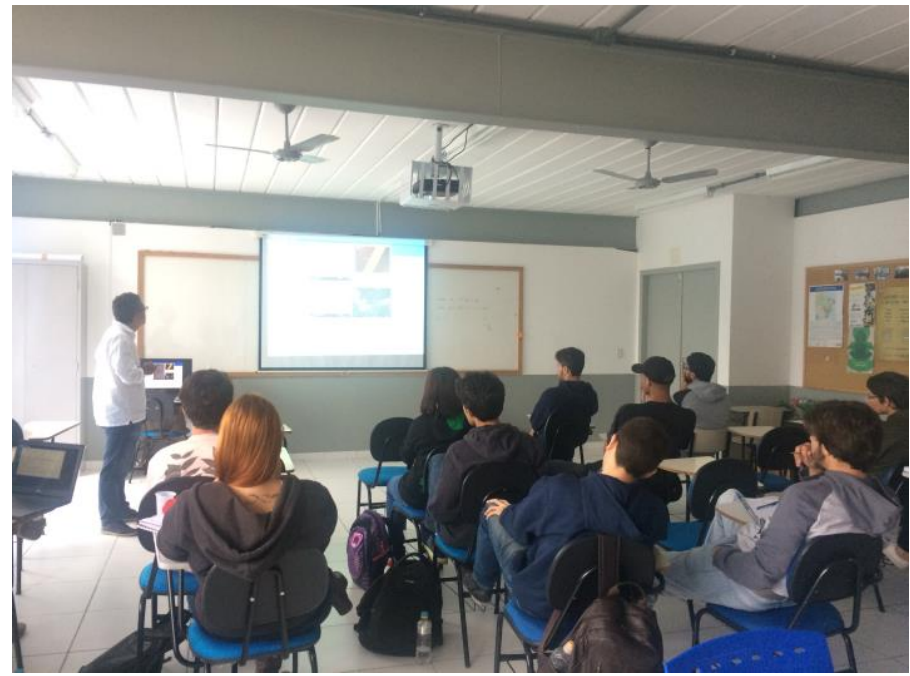

Figura 10: Palestra "Energias Renováveis"

O "Projeto Domo Geodésico" (Fig.11), capacitou os monitores a tratar e manusear o bambu para a construção do domo, assim como, a dar nós específicos utilizados em construção de estruturas estáveis.

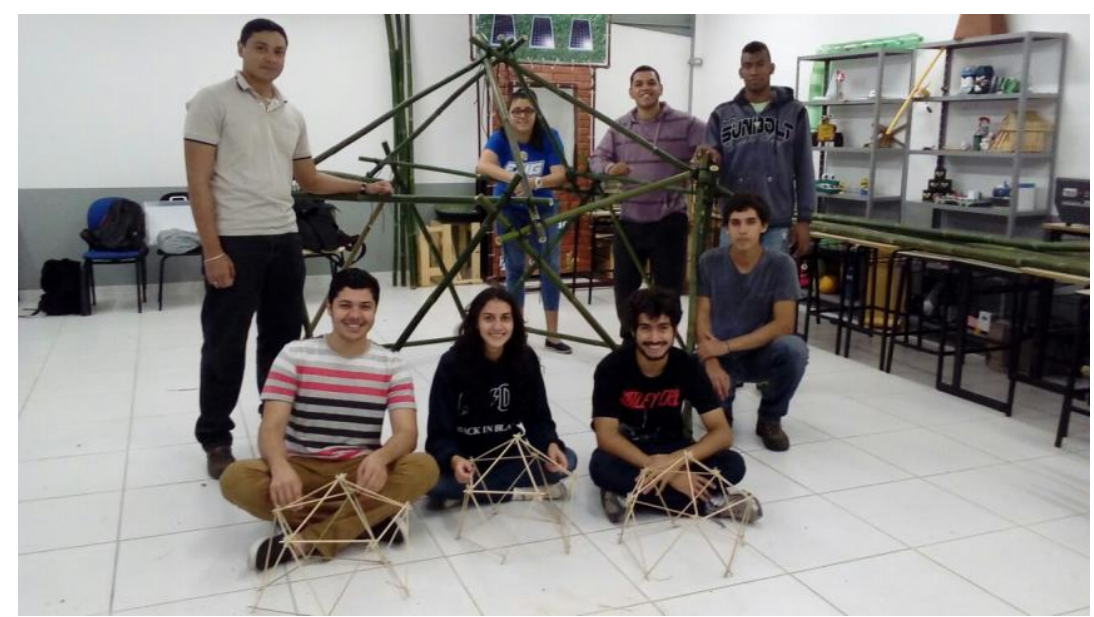

Figura 11: Projeto Domo Geodésico Parte II

A coordenação da Sala Verde está compondo a equipe de orientação de dois alunos do Curso de Engenharia Civil, que trará como proposta de seu 
TCC a construção de estruturas alternativas de pau a pique. De acordo com o andamento das pesquisas, tem-se a proposta de implementação da construção de um espaço de convivência no Quilombo de Santana, localizado no Município de Quatis, e outro no Lixão de Bulhões, localizado no Município de Porto Real (Fig.12).

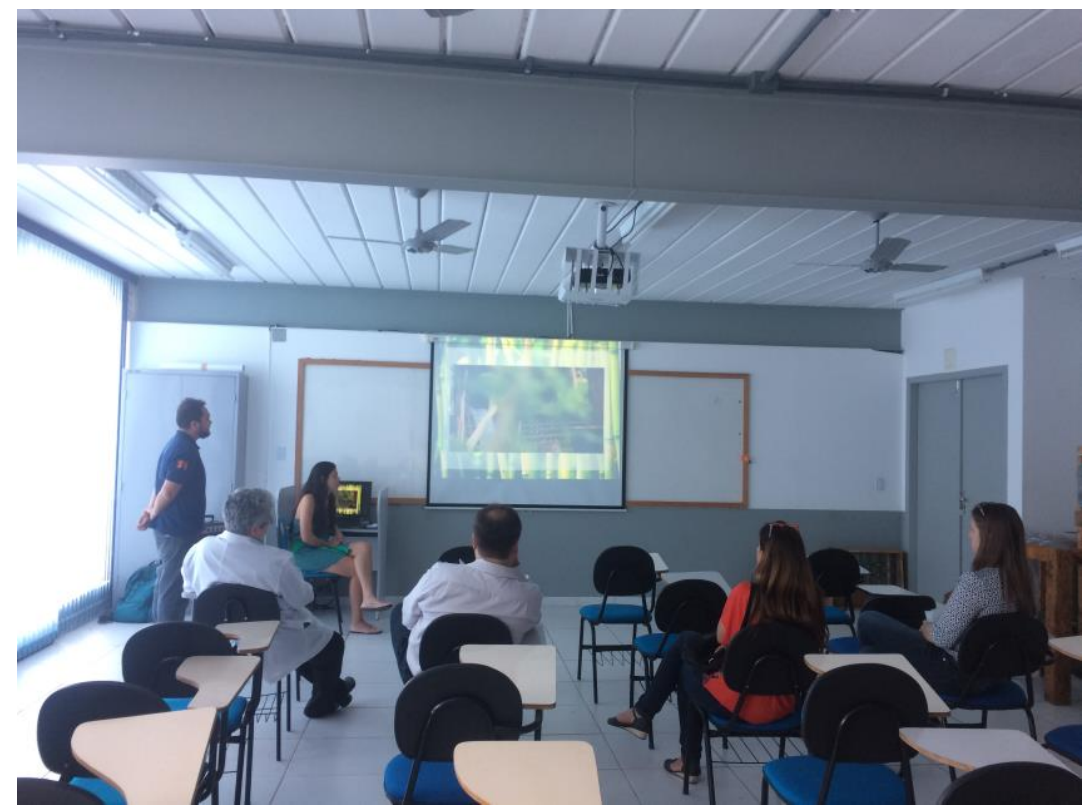

Figura 12: Projeto Construtivo

Com base em uma proposta de sustentabilidade foi proposta uma oficina de produção do sabão ecológico para os discentes do UniFOA. O sabão ecológico (Fig. 13) é produzido a partir do óleo de cozinha já utilizado, evitando que o mesmo seja descartado inadequadamente no ambiente. 

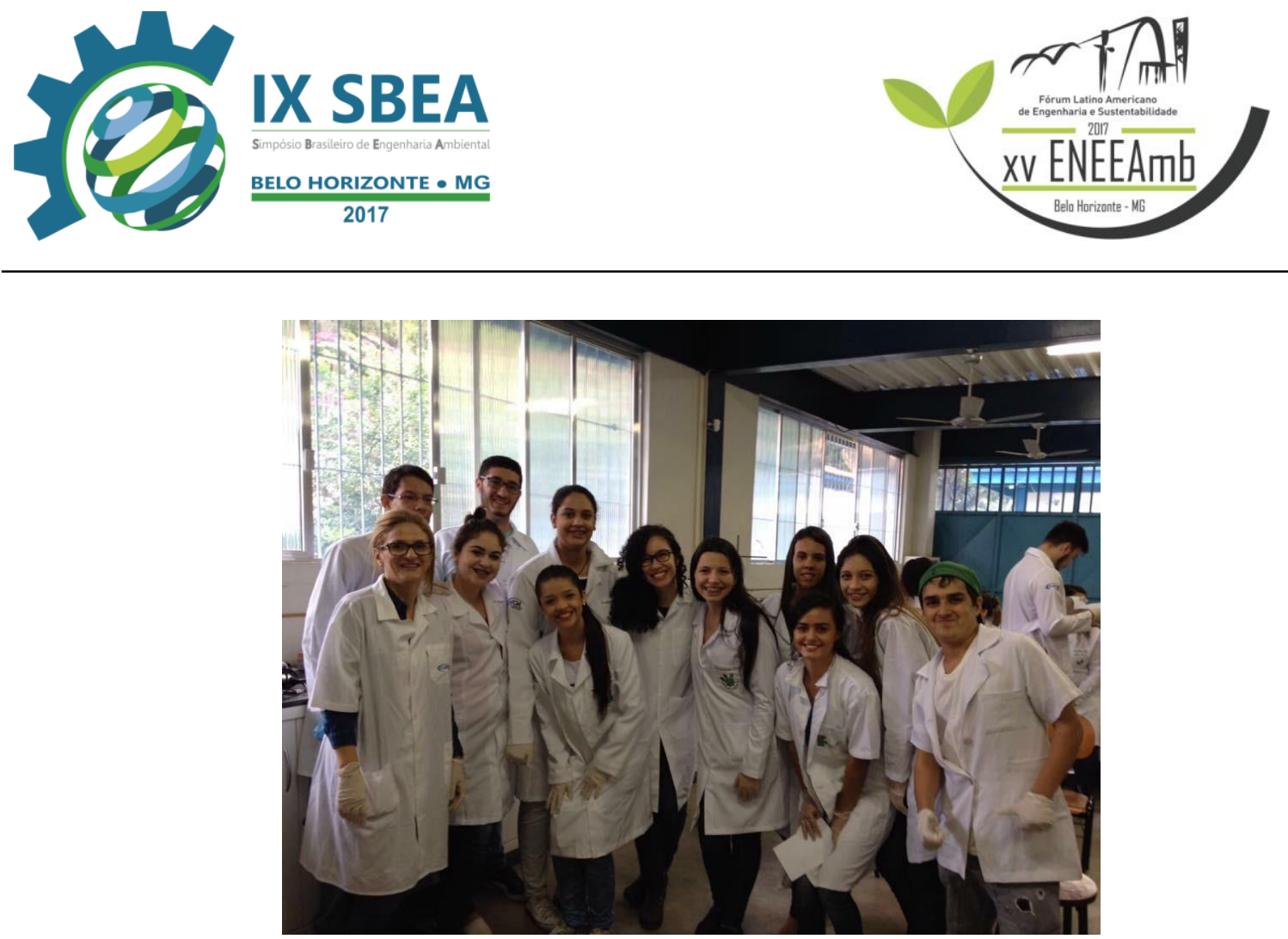

Figura 13: Sabão Ecológico

Ocorreu também esse ano uma palestra (Fig. 14) sobre as mudanças climáticas e os impactos que elas geram no planeta.

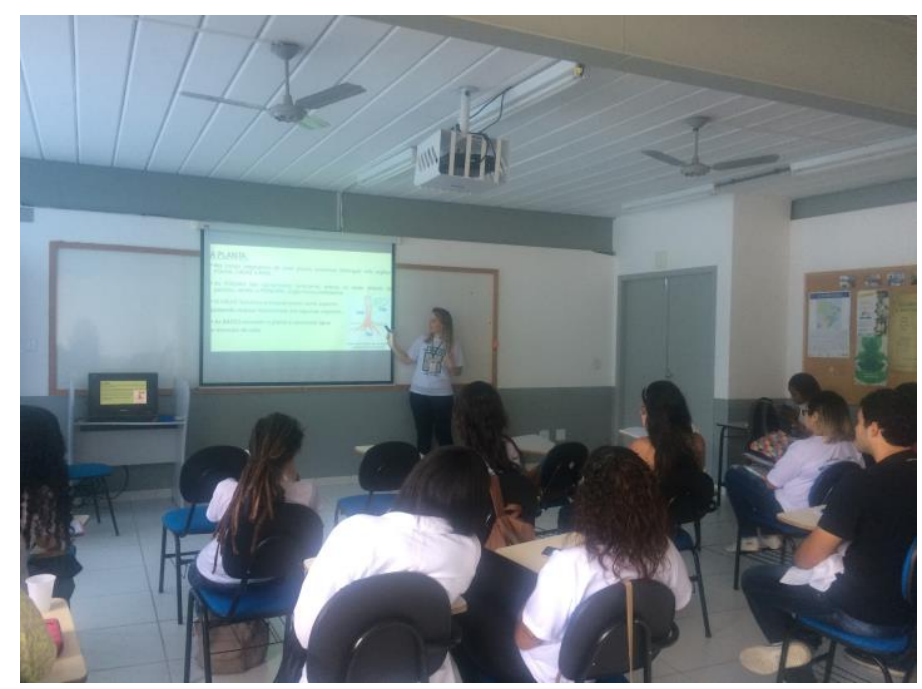

Figura 14: Palestra "Mudanças Climáticas e seus impactos:

\section{passado, presente e futuro"}

O UniFOA possui um evento conhecido como UniFOA de Portas Abertas (Fig 15), o qual recebe alunos do ensino médio da região. Nesse dia a Sala Verde 


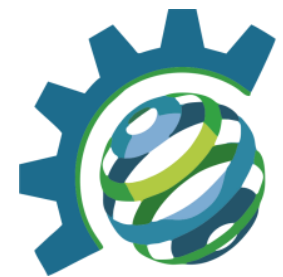

montou seu Domo Geodésico para divulgar a mesma para os alunos e professores presentes nesse evento.

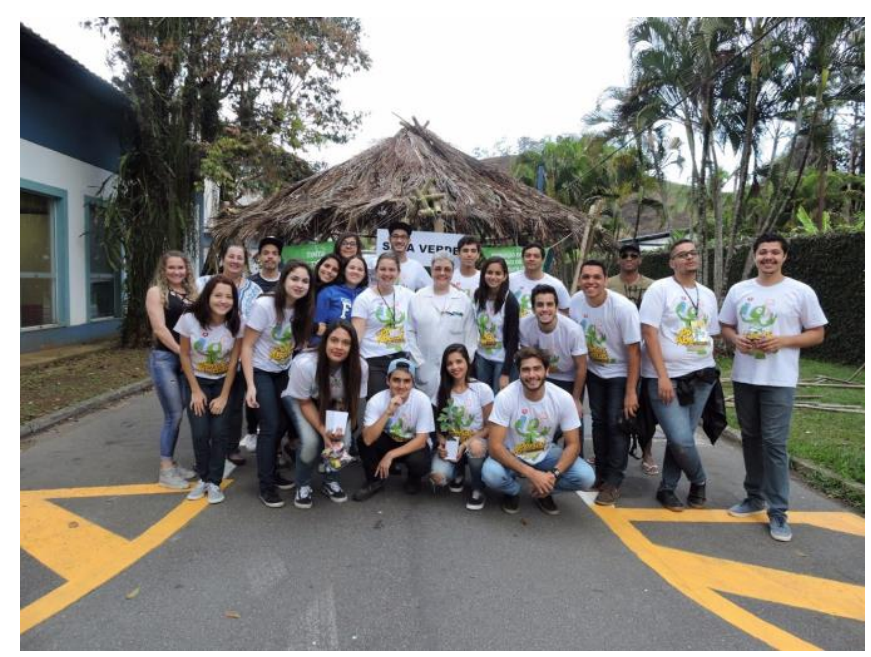

Figura 15: UniFOA de Portas Abertas

Os alunos do curso técnico de Meio Ambiente do IFRJ de Pinheiral, receberam uma palestra sobre a "Recuperação de áreas degradas" (Fig. 16). O Objetivo da palestra foi expor os possíveis problemas que uma área degrada pode ter, e ensinar como começar a recuperá-la.

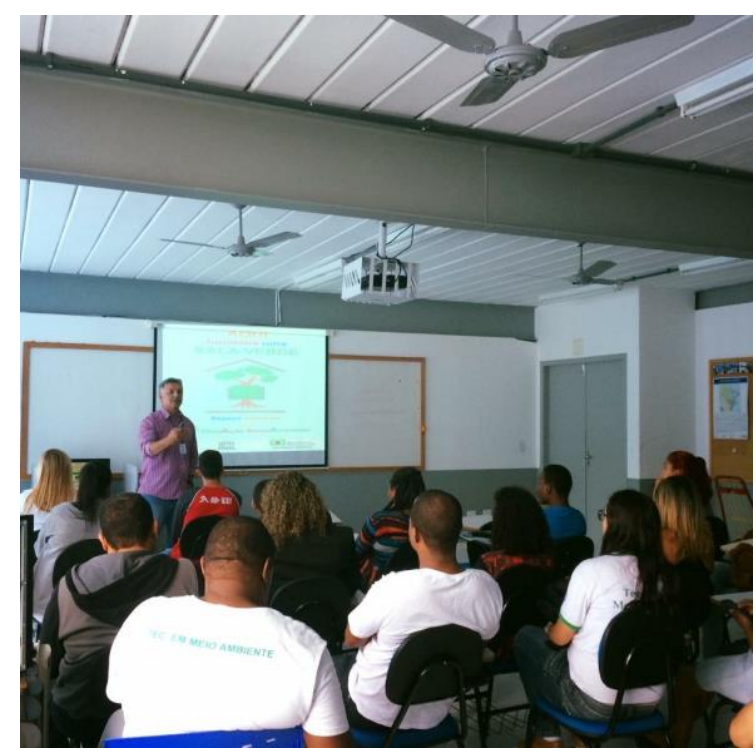

Figura 16: Palestra "Recuperação de áreas degradas" 
O projeto Sala Verde Paraíba do Sul, foi apresentado no II Encontro de Extensão do UniFOA, ganhando como melhor projeto de extensão proposto no evento (Fig.17).

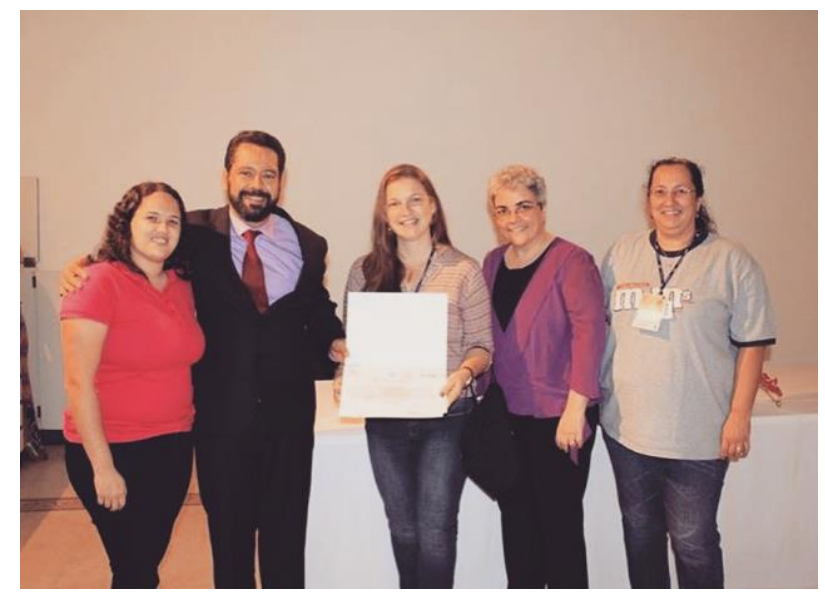

Figura 17: II Encontro de Extensão do UniFOA

Os monitores da Sala Verde, juntamente com a Defensoria Pública da União - DPU de Volta Redonda realizaram uma ação no Lixão de Resende (Fig. 18), a qual contou com uma palestra sobre "Noções da Lei da Política Nacional dos Resíduos Sólidos - Lei no 12.305/2010” e também com atendimentos na área de Medicina, Engenharia Ambiental e Jornalismo. 

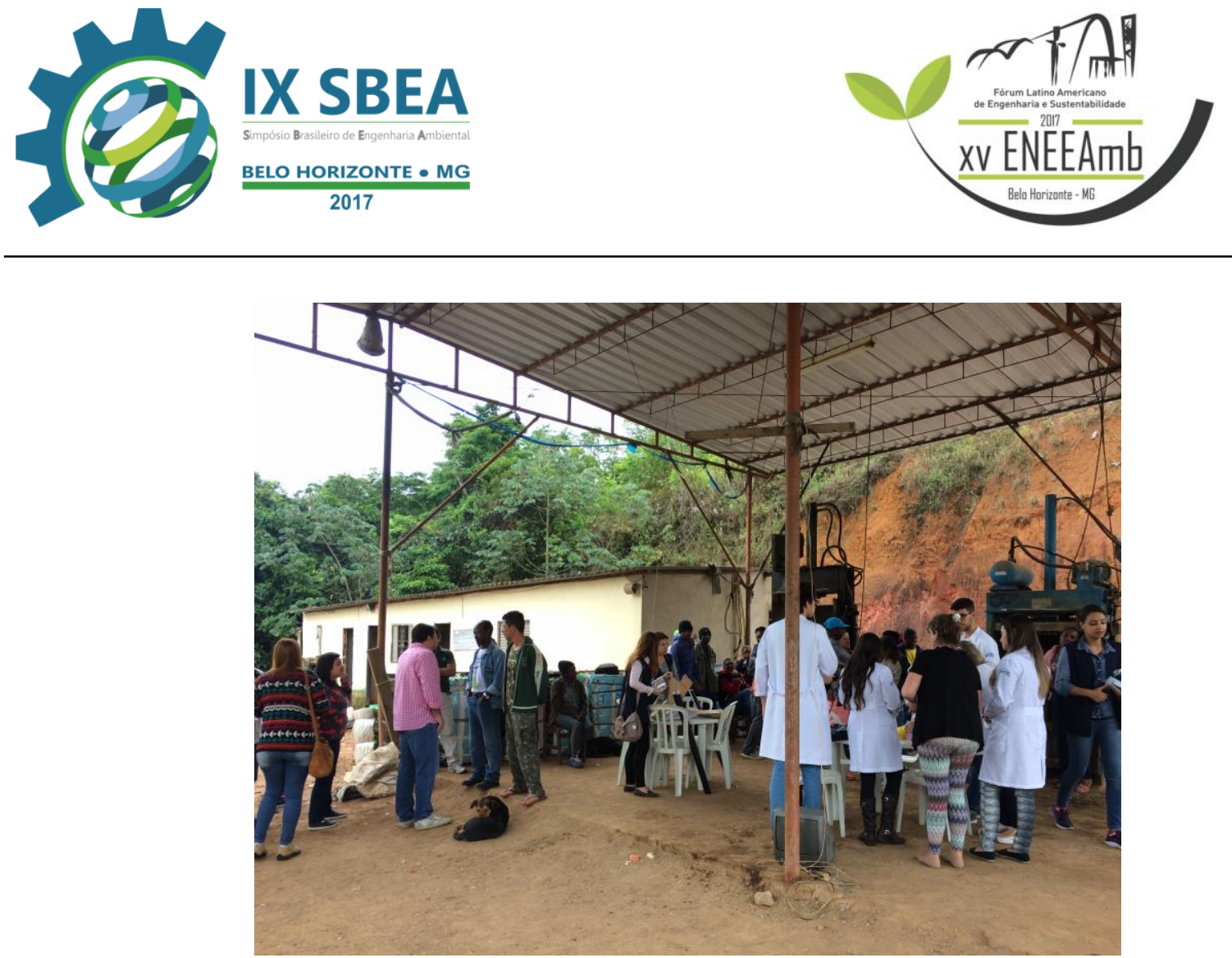

Figura 18: Lixão de Resende

Realização de oficina (Fig.19) para ensinar a população como fazer tinta de terra e também como fazer um quadro negro.

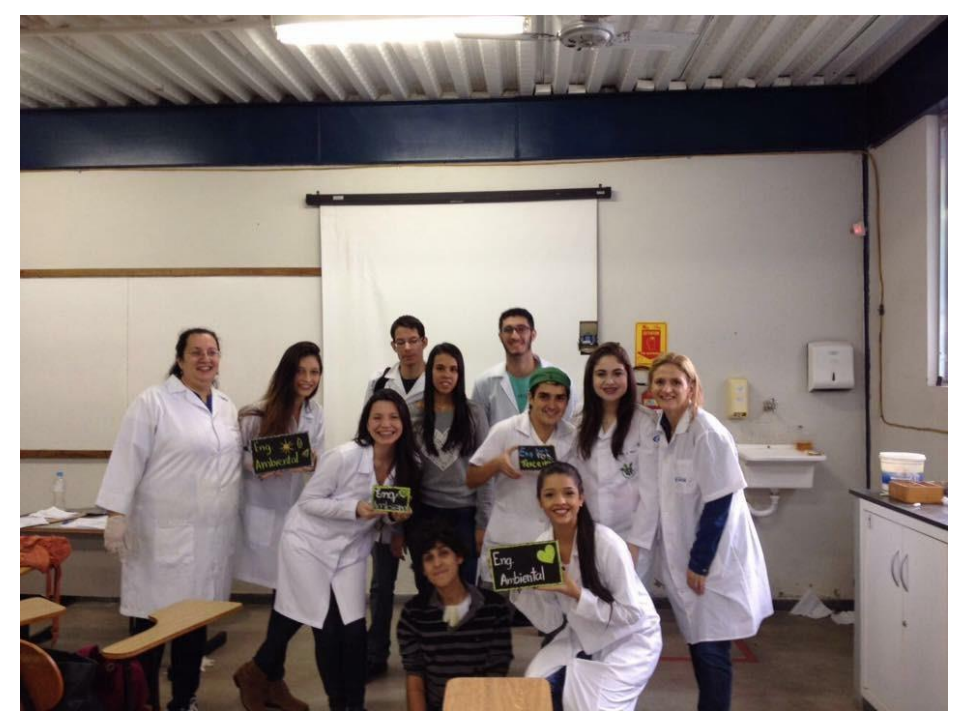

Figura 19: Oficina de Tinta de terra e Quadro Negro

Palestra na temática da sustentabilidade (Fig. 20) no evento da SIPAT na Empresa Abreu, localizada na cidade de Volta Redonda. 


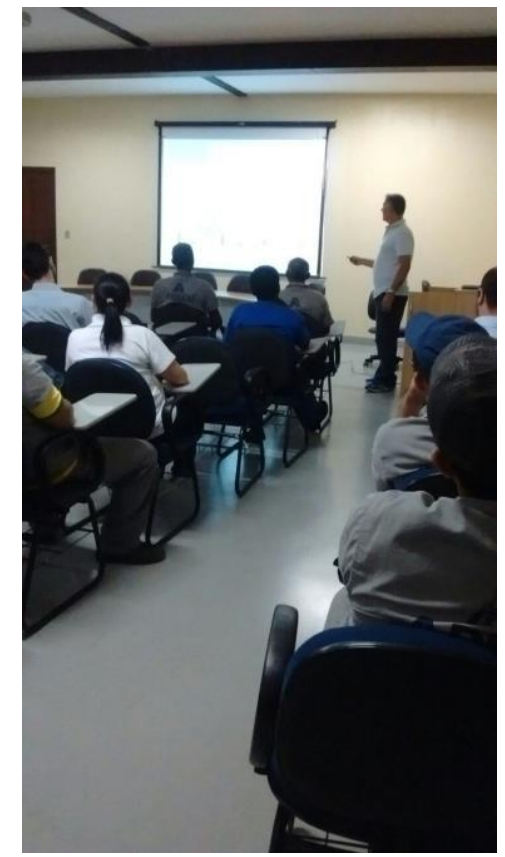

\section{Figura 20: Palestra "Sustentabilidade"}

Com o objetivo de facilitar o acesso dos interessados à Sala Verde foi proposta a uma aluna do curso de Publicidade e Propaganda o desenvolvimento de um site (Fig.21) através do programa de estágio institucional. A aluna contou com a ajuda de um Designer para desenvolvêlo (http://web.unifoa.edu.br/salaverde/default.asp).

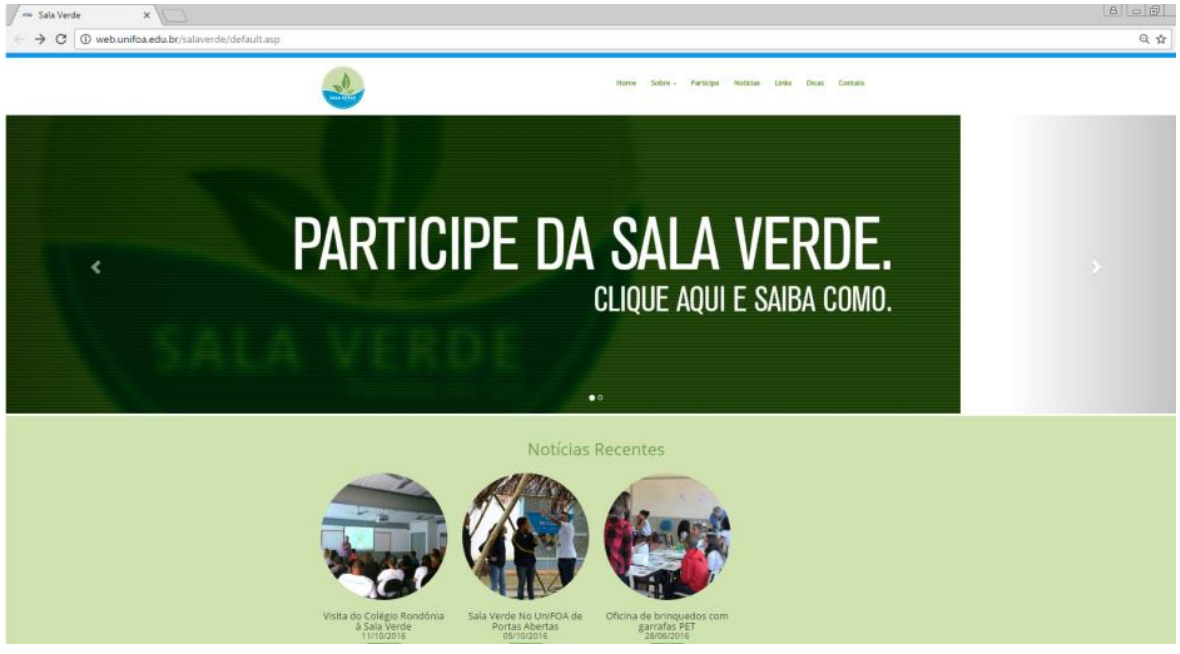

Figura 21: Site Sala Verde Paraíba do Sul 


\section{CONCLUSÕES/RECOMENDAÇÕES}

Frente aos resultados obtidos nas diferentes ações realizadas pela Sala Verde Paraíba do Sul, pode-se comprovar que a educação ambiental é um processo e não um produto. Dessa forma, a busca pelo seu aperfeiçoamento deve ser uma constante. $\mathrm{O}$ trabalho conjunto de profissionais de diferentes áreas de conhecimento técnico, apoiado na vontade de realizar ações concretas e eficazes funcionam como combustível na busca de uma melhoria da qualidade de vida da população e o equilíbrio ambiental do planeta. 


\section{REFERÊNCIAS BIBLIOGRÁFICAS}

1. MINISTERIO DO MEIO AMBIENTE Disponível em:

http://www.mma.gov.br/educacao-ambiental/educomunicacao/salasverdes\#oprojeto Acesso em: 12 jun 2015.

2. AMÂNCIO, C. O. Por que da educação ambiental? Corumbá, MS: Embrapa Pantanal, 2005. 3p. ADM - Artigo de Divulgação na Mídia, n.109. Acesso em: 11 jun 2015.

3. D'ISEP, C. F. M.; NERY JR, N.; MEDAUAR, O. Políticas Públicas Ambientais. São Paulo: Revista dos Tribunais. 2009.

4. REIS, M. F.; FLECK, E. Controle e riscos ao descartar o óleo. Disponível em:

http://www.eccosystems.com.br/2008/artigos/biodiesel/DESTINACAOOLE ODEFRITURA-ABES.pdf. Acesso em: 11 jun 2015. 